\title{
Pengaruh Implementasi Knowledge Management dan Stres Kerja Terhadap Kinerja Karyawan pada PT. Asaputex Jaya Kota Tegal
}

Manajemen Sumber Daya Manusia

\author{
Meitoni Sugiarto"), Jaka Waskito ${ }^{2)}$, Mahben Jalil ${ }^{3)}$
}

Fakultas Ekonomi dan Bisnis, Universitas Pancasakti, Tegal meitonisugiarto@gmail.com, jaka.wsk@yahoo.co.id,jalilmahben@gmail.com

\section{Abstract}

The puprpose of research: 1) To determine the effect of knowledge management on the performance of employees at PT. Asaputex Jaya. 2) To find out the influence of work stress on the performance of employees at PT. Asaputex Jaya. 3) To find out the influence of knowledge management and stress work variables together - on the performance of employees at PT. Asaputex Jaya. The method used in this study is an associative causal method. This research method uses a survey dividing questionnaire questionnaire. While the data analysis method used is testing validity and reliability, rank spearman correlation analysis, multiple correlation coefficient analysis, multiple correlation test significance, analysis of determination coefficient ( $R$ square). Based on the results of the study there are 1 ) there is an influence between knowledge management on employee performance this is evidenced from the results of data analysis in this study obtained correlation coefficient $(r)$ of 0.436 with a sig value $=0,000<0.05$. 2) there is an influence between work stress on employee performance this is evidenced from the results of data analysis in this study obtained correlation coefficient ( $r$ ) of 0.496 with sig value $=0,000<0.05$. 3) there is an influence between knowledge management and work stress on employee performance this is evidenced from the results of data analysis in this study obtained correlation coefficient $(r)$ of 0.573 with a sig value of $0.000<0.005$.

\section{Keywords: Knowledge Management, Job Stress, Employee Performance}

\begin{abstract}
Abstrak
Tujuan penelitian : 1) Untuk mengetahui adanya pengaruh knowledge management terhadap kinerja karyawan pada PT. Asaputex Jaya. 2) Untuk mengetahui adanya pengaruh stress kerja terhadap kinerja karyawan pada PT. Asaputex Jaya. 3) Untuk mengetahui adanya pengaruh antara variabel knowledge management dan stress kerja secara bersama sama terhadap kinerja karyawan pada PT. Asaputex Jaya. Metode yang digunakan dalam penelitian ini adalah metode kausal asosiatif (causal assosiative research). Metode penelitian ini menggunakan survey membagi angket kuesioner. Sedangkan metode anaisis data yang digunakan adalah pengujian validitas dan reliabiltas, analisis korelasi rank spearman, analisis koefesien korelasi berganda, uji signifikansi korelasi berganda, analisis koefesien determinasi ( $\mathrm{R}$ square). Berdasarkan hasil penenitian terdapat 1) terdapat pengaruh antara knowledge management terhadap kinerja karyawan hal ini dibuktikan dari hasil analisis data pada penelitian ini diperoleh koefesien korelasi (r) sebesar 0,436 dengan nilai sig $=0,000<0,05$. 2) terdapat pengaruh antara stress kerja terhadap kinerja karyawan hal ini dibuktikan dari
\end{abstract}


hasil analisis data pada penelitian ini diperoleh koefesien korelasi (r) sebesar 0,496 dengan nilai sig $=0,000<0,05.3$ ) terdapat pengaruh antara knowledge management dan stress kerja terhadap kinerja karyawan hal ini dibuktikan dari hasil analisis data pada penelitian ini diperoleh koefesien korelasi (r) sebesar 0,573 dengan nilai sig 0,000 <0,005.

\section{Kata kunci : Knowledge Management, Stres Kerja, Kinerja Karyawan}

\section{Pendahuluan}

Dewasa ini di era globalisasi era sekarang menuntut untuk mengambil keputusan dalam hal strategi yang tepat agar dapat bersaing dilingkungn industri yang semakin ketat dan kompetetif. Peningkaan kualitas efektfitas didalam organisasi tidak hanya tergantung pada peralatan - peralatan yang ada didalam kantor, tetapi perusahaan juga harus mengelola sumber daya manusia.

Pengelolaan pengetahuan juga tidak terlepas dari pengelolaan sumber daya manusia sebagai asset penting perusahan atau organisasi. Hal itu disamping sebagai sumber pengetahuan, manusia pada hakekatnya juga merupakan pelaku dari proses - proses yang ada didalam manajemen pengetahuan. Banyak perusahaan atau organisasi belum mengetahui potensi pengetahuan tersembunyi yang dimiliki karyawannya.

Mengingat peraingan dalam bisnis dibutuhkan kualitas dan mutu bagi pekerja dengan cara penerapan pengelolaan penegetahuan (knowledge). Disamping pengelolaan ketamprilan harus sesuai dengan kopetensi dan kebutuhan organisasi. Karena dalam hal ini bahwa knowledge harus dikelola ( managed) harus direncanakan dan diimplementasikan.

Manajer menempatkan pengetahuan sebagai sumber daya penggerak organisasi, sehingga menjadi organisasi yang kompetetif dan berdaya saing. Ketika seorang meninggalkan perusahaan, perusahan harus menyadari bahwa mereka pergi dengan membawa knowledge yang sangat berharga. Sejarah membuktikan bahwa perusahaan - perusahaan yang maju dan dapat bertahan dengan baik dari zaman ke zaman adalah perusahaan yang memiliki kemampuan untuk mengelola pengetahuan yang dimilikinya dengan baik.

Hal ini dikarenakan pengetahuan merupakan sumber daya utama dan memiliki peran penting untuk pencapaian keunggulan kompetitif berkelanjutan. Mengapa pengetahuan bisa membuat keunggulan bersaing mampu bertahan? Kata kuncinya adalah pengetahuan cenderung berharga, langka, sulit ditiru, dan sulit digantikan.

Permasalahan mengenai kinerja merupakan permasalahan yang akan selalu dihadapi oleh pihak manajemen perusahaan, karena itu manajemen perlu mengetahui faktor-faktor yang mempengaruhi kinerja karyawan.

Faktor-faktor yang dapat mempengaruhi kinerja karyawan tersebut akan membuat manajemen perusahaan dapat mengambil berbagai kebijakan yang diperlukan, sehingga dapat meningkatkan kinerja karyawannya agar sesuai dengan harapan perusahaan.

Faktor-faktor yang mempengaruhi kinerja karyawan diantaranya yaitu : Quality (kualitas), Quantity (kuantitas), timeless (waktu kurang), need supervision (butuhan kepengawasan), dan interperconal impact (dampak antar perusahaan). Faktor-faktor tersebut berpengaruh terhadap karyawan dalam melaksanakan tugas-tugas yang diberikan kepadanya, sehingga hasil akhirnya adalah kinerja karyawan itu sendiri, apakah akan semakin baik atau semakin buruk. Lebih lanjut kinerja karyawan akan mencapai hasil yang lebih maksimal apabila didukung dengan knowledge yang dimiliki. 
Setiap karyawan diharapkan dapat terus menggali pengetahuannya dan tidak hanya bergantung atau terpaku pada sistem yang ada. Sehingga dapat dikatakan bahwa setiap karyawan mempunyai peran di dalam meningkatkan perusahaannya.

Permasalahan mengenai kinerja merupakan permasalahan yang akan selalu dihadapi oleh pihak manajemen perusahaan, karena itu manajemen perlu mengetahui faktor-faktor yang mempengaruhi kinerja karyawan. Faktor-faktor yang dapat mempengaruhi kinerja karyawan tersebut akan membuat manajemen perusahaan dapat mengambil berbagai kebijakan yang diperlukan, sehingga dapat meningkatkan kinerja karyawannya agar sesuai dengan harapan perusahaan.

Dengan melihat faktor-faktor yang mempengaruhi retensi karyawan tersebut, penelitian ini menggunakan knowledge management (X1) yang terdiri dari indikator - indikor sebagai berikut, diataranya : people, procces ,dan technology. Sebagai variabel yang mendukung penelitian dan variabel stres kerja (X2) dengan variabel dependen (Y) yaitu kinerja karyawan pada PT. Asaputex Jaya.

Perusahaan tentu akan mengalami kerugian jika ada beberapa seorang karyawan yang mengalami stres kerja, sehingga menurunkan kinerjanya. Perusahaan harus mengadakan adanya knowledge management sebagai asset karyawan untuk meningkatkan mutu dan kualitas produk yang dihasilkan oleh perusahaan.

Mengingat permasalahan yang dihadapi perusahaan pentingnya knowledge management sebagai asset untuk karyawan berorganisasi guna meningkatkan menambah ide ide baru yang dapat dihasilkan oleh para karyawan serta stress kerja sebagai antisipasi kejenuhan para karyawan untuk bekerja hanya di salah satu bidang saja.

\subsection{Rumusan Masalah}

Berdasarkan penjelasan latar belakang di atas, maka dapat dirumuskan permasalahan sebagai berikut :

1. Apakah terdapat pengaruh Knowledge management terhadap kinerja karyawan pada PT. Asaputex Jaya?

2. Apakah terdapat pengaruh stress kerja terhadap kinerj karyawan pada PT. Asaputex Jaya?

3. Apakah terdapat pengaruh antara knowledge management dan stress kerja terhdap kinerjaa karyawan pada PT. Asaputex Jaya?

\subsection{Tujuan Penelitian}

Adapun tujuan dari penelitian ini adalah sebagai berikut :

1. Untuk mengetahui adanya pengaruh knowledge management terhadap kinerja karyawan pada PT. Asaputex Jaya.

2. Untuk mengetahui adanya pengaruh stress kerja terhadap kinerja karyawan pada PT. Asaputex Jaya.

3. Untuk mengetahui adanya pengaruh antara knowledge management dan stress kerja terhadap kinerja karyawan pada PT. Asaputex Jaya.

\section{Kerangka Pemikiran Dan Hipotesis}

Pada penelitian ini, peneliti ingin mengetahui pengaruh variabel knowledge management dan stress kerja terhadap kinerja karyawan,yaitu :

1. Pengaruh knowledge management terhadap kinerja karyawan

Manajemen pengetahuan (knowledge management) ialah suatu rangkaian kegiatan yang digunakan oleh organisasi atau perusahaan untuk mengidentifikasi, menciptakan, menjelaskan, dan mendistribusikan pengetahuan untuk digunakan kembali, diketahui, dan dipelajari di dalam organisasi. Kegiatan ini biasanya terkait dengan objektif organisasi dan ditujukan untuk mencapai suatu hasil tertentu 
seperti pengetahuan bersama, peningkatan kinerja, keunggulan kompetitif, atau tingkat inovasi yang lebih tinggi.

Menurut (Wulantika,2009:46)

knowledge management merupakan kegiatan organisasi dalam mengelola pengetahuan dan dijadikan sebagai aset, dalam berbagai strateginya ada penyaluran pengetahuan yang tepat kepada orang yang tepat dan dalam waktu yang cepat, hingga mereka bisa saling berinteraksi, berbagi pengetahuan dan mengaplikasikannya dalam pekerjaan sehari-hari demi peningkatan kinerja organisasi. Knowledge management bukanlah merupakan tujuan akhir sebuah perusahaan ,melainkan merupakan metode agar perusahaan selalu mempunyai energi untuk melakukan kreasi dan inovasi dalam waktu yang cepat sehingga perusahaan dapat mempertahankan daya hidupnya.

Pengertian kinerja atau Performance merupakan gambaran mengenai tingkat pencapaian pelaksanaan suatu program kegiatan atau kebijakan dalam mewujudkan sasaran, tujuan visi dan misi organisasi yang di tuangkan melalui perencanaan strategi suatu organisasi.

Kinerja merupakan hasil kerja secara kualitas dan kuantitas yang dapat dicapai oleh seorang pegawai dalam melaksanakan tugas sesuai dengan tanggung jawab yang diberikan kepadanya.

Jadi, dapat disimpulkan bahwa pengaruh knowledge management dengan kinerja karyawan adalah dalam suatu kegiatan perusahaan memberikan sebuah pengetahuan kepada bawahanya untuk mengerti tugas tugasnya dalam bekerja serta memahami pertauran yang ada diperusahaan dlam hal ini dapat meningkatkan kinerja karyawan pada perusahaan.

2. Pengaruh stress kerja terhadap kinerja karyawan

Stres kerja adalah sesuatu kondisi ketegangan yang menciptakan adanya ketidak seimbangan fisik dan psikis yang mempengaruhi emosi, proses berpikir, dan kondisi seorang karyawan (Rivai, 2004:108).

Orang-orang yang mengalami stres menjadi nerves dan merasakan kekuatiran kronis sehingga mereka sering menjadi marah-marah, agresif, tidak dapat relaks, atau memperlihatkan sikap yang tidak kooperatif (Hasibuan, 2012:204).

Pengertian kinerja atau Performance merupakan gambaran mengenai tingkat pencapaian pelaksanaan suatu program kegiatan atau kebijakan dalam mewujudkan sasaran, tujuan visi dan misi organisasi yang di tuangkan melalui perencanaan strategi suatu organisasi.

Kinerja merupakan hasil kerja secara kualitas dan kuantitas yang dapat dicapai oleh seorang pegawai dalam melaksanakan tugas sesuai dengan tanggung jawab yang diberikan kepadanya.

Jadi, dapat disimpulkan bahwa pengaruh stress kerja terhadap kinerja karyawan adalah dalam pemberian tugas tentunya perusahaan melihat kemampuan seorang karyawan agar tidak terjadi kejenuhan oleh karyawan sehingga dapat mengakibatkan stress yang menimbulkan penurunan kinerja pada karyawan.

Berdasarkan uraian di atas, maka kerangka berpikir antara knowledge management dan stress kerja terhadap kinerja karyawan dapat digambarkan sebagai berikut : 


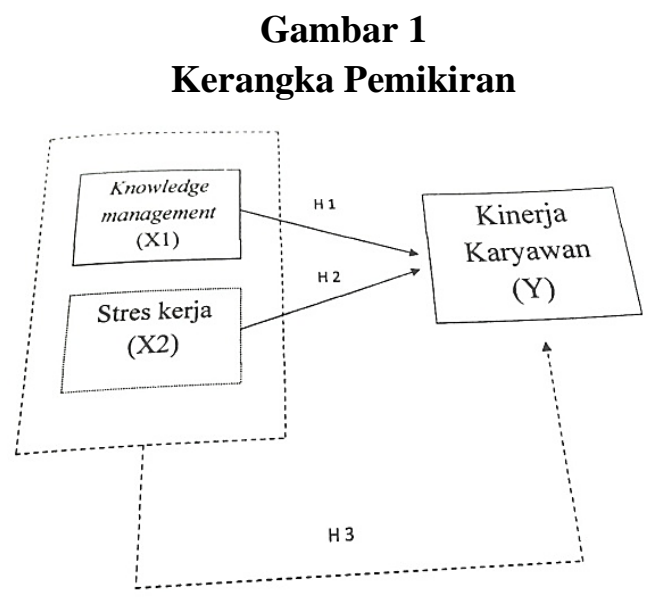

\subsection{Hipotesis}

Hipotesis adalah suatu pernyataan sementara atau dugaan yang masih harus dicari kebenarannya. Hipotesis dalam penelitian ini adalah :

1. Terdapat pengaruh knowledge management terhadap kinerja karyawan pada PT. Asaputex Jaya Kota Tegal.

2. Terdapat pengaruh stress kerja terhadap kinerja karyawan pada PT. Asaputex Jaya Kota Tegal.

3. Terdapat pengaruh knowledge management dan stress kerja terhadap kinerja karyawan pada PT. Asaputex Jaya Kota Tegal.

\section{Metode Penelitian}

Penelitian ini menggunakan jenis penelitian kuantitatif. Penelitian kuantitatif adalah proses menemukan pengetahuan yang menggunakan data berupa angka sebagai alat menganalisis keterangan mengenai apa yang ingin diketahui (Modul Metodologi Penelitian, 2017:8).

Dalam penelitian ini menggunakan tipe penelitian deskriptif, yaitu bertujuan untuk melukiskan atau menggambarkan keadaan di lapangan secara sistematis dengan fakta fakta dengan interpretasi yang tepat dan data yang saling berhubungan serta bukan hanya untuk mencari kebenaran antara variabelnya (Sugiyono, 2010:35).

Sedangkan untuk metode yang digunakan adalah dengan metode survei, yaitu cara yang dilakukan dengan menggunakan angket (kuesioner) sebagai alat penelitian yang dilakukan pada populasi besar maupun kecil, tetapi data yang dipelajari adalah data yang diambil dari populasi tersebut (Sugiyono, 2013:11).

\subsection{Populasi Dan Sampel}

a. Populasi

Populasi adalah wilayah generalisasi yang terdiri atas objek atau subyek yang mempunyai kuantitas dan karakteristik tertentu yang ditetapkan oleh peneliti untuk dipelajari dan kemudian dan ditarik kesimpulannya (Sugiyono, 2017:61). Populasi dalam penelitian ini adalah seluruh karyawan pada PT. Asaputex Jaya sebnyak 65 karyawan.

b. Sampel

Sampel adalah bagian dari jumlah dan karakteristik yangdimiliki oleh populasi. Teknik pengambilan sampel yang digunakan adalah menggunakan sampel jenuh, yaitu seluruh populasi dijadikan sampel sehinggal sampel yang digunakan berjumlah 65 karyawan.

3.2 Definisi Konseptual Dan Operasional Variabel

Definisi konseptual merupakan pengertian secara umum mengenai variabel yang akan dianalisis. Definisi ini lebih bersifat hipotikal dan tidak dapat diobservasi.

Definisi operasional adalah batasan pengertian tentang variabel yang didalamnya sudah mencerminkan indikator-indikator yang akan digunakan untuk mengukur variabel yang bersangkutan.

Variabel penelitian adalah segala sesuatu yang berbentuk apa saja yang ditetapkan oleh peneliti untuk dipelajari sehingga diperoleh informasi tentang hal tersebut, kemudian ditarik kesimpulannya 
(Sugiyono, 2017:2). Yang menjadi variabel dalam penelitian ini adalah knowledge management $\left(\mathrm{X}_{1}\right)$, stress kerja $\left(\mathrm{X}_{2}\right)$ dan kinerja karyawan(Y) dan dijelaskan sebagai berikut :

\section{Tabel 1}

Operasional Variabel

\begin{tabular}{|c|c|c|c|}
\hline Variabel & Dimensi & Indikstor & $\begin{array}{l}\text { Nomor Item } \\
\text { Pertanyaan }\end{array}$ \\
\hline \multirow{8}{*}{$\begin{array}{l}\text { Kineija } \\
\text { karyawan } \\
\text { Sumber: } \\
\text { Masana } \\
\text { Sembiring } \\
(2012: 81)\end{array}$} & Kualitas kerja & $\begin{array}{l}\text { 1. Tingkat kesalahan } \\
\text { dalam bekerja }\end{array}$ & \multirow{8}{*}{$\begin{array}{l}\text { SS: Sangat Setuju } \\
\text { S : Setuju } \\
\text { N : Netral } \\
\text { TS : Tidak Setuju } \\
\text { STS : Sangat } \\
\text { Tidak S etuju }\end{array}$} \\
\hline & & $\begin{array}{l}\text { 2. Keberhasilan keij } \\
\text { seti ap laryaw an }\end{array}$ & \\
\hline & \multirow[t]{2}{*}{ Kuantitas kerja } & $\begin{array}{l}\text { 1. Jumlah hasil kerja } \\
\text { yang dihasillan }\end{array}$ & \\
\hline & & $\begin{array}{l}\text { 2. Jumlah tugas keja } \\
\text { yang diberikan }\end{array}$ & \\
\hline & \multirow[t]{2}{*}{ Timeless } & $\begin{array}{l}\text { 1. Tidak menunda } \\
\text { pekerjaan }\end{array}$ & \\
\hline & & $\begin{array}{l}\text { 2. Pekerjazn selesai } \\
\text { sesuai batas waktu }\end{array}$ & \\
\hline & \multirow[t]{2}{*}{ Nesd suparvision } & $\begin{array}{l}\text { 1. Menyeles zikan } \\
\text { tugas dengan baik } \\
\text { dan benar }\end{array}$ & \\
\hline & & $\begin{array}{l}\text { 2. Mengerjakan tug as } \\
\text { tanpa diawasi atav } \\
\text { mandiil }\end{array}$ & \\
\hline
\end{tabular}

\begin{tabular}{|c|c|c|c|}
\hline $\begin{array}{l}\text { Knowleage } \\
\text { management } \\
\text { Sumber: } \\
\text { Bhoj araju } \\
(2005: 38)\end{array}$ & Technology & 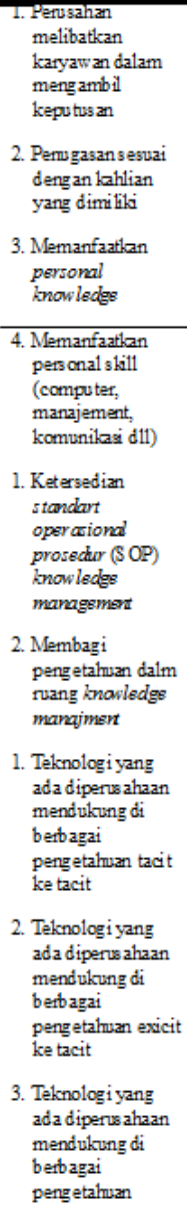 & $\begin{array}{l}\text { SS: Sangat Setuju } \\
\text { S : Setuju } \\
\text { N : Netral } \\
\text { TS : Tidak Setuju } \\
\text { STS : Sang at } \\
\text { Tidak S etuju }\end{array}$ \\
\hline
\end{tabular}

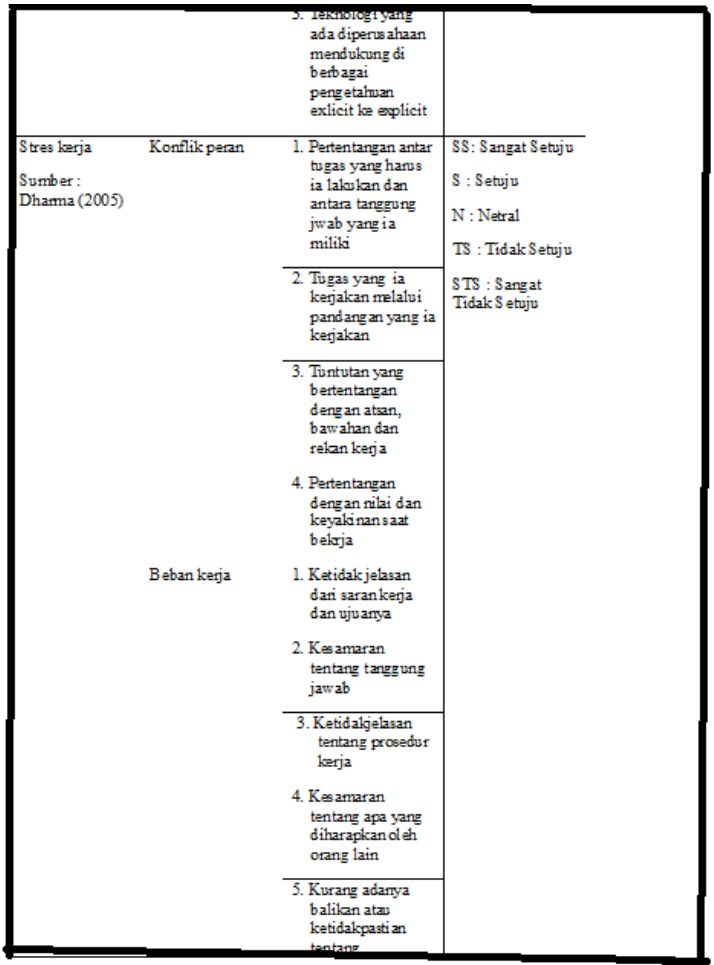

\subsection{Teknik Pengumpulan Data}

Teknik pengumpulan data yang dilakukan dalam penelitian ini adalah :

a. Wawancara (Interview)

Wawancara adalah teknik pengumpulan data apabila peneliti ingin melakukan studi pendahuluan untuk menemukan permasalahan yang harus diteliti (Sugiyono, 2010:194).

b. Kuesioner (Angket)

Kuesioner adalah teknik pengumpulan data yang dilakukan dengan cara memberi seperangkat pertanyaan atau pertanyaan tertulis kepada responden untuk dijawabnya (Sugiyono, 2010:199).

c. Observasi

Observasi adalah teknik pengumpulan data yang mempunyai ciri spesifik kepada orang dan obyek alam yang lain (Sugiyono, 2010:203).

\subsection{Metode Analisis Data}

Metode analisis data yang digunakan dalam penelitian ini adalah :

1. Analisis Korelasi Rank Spearman 
Digunakan untuk mencari hubungan atau untuk menguji signifikansi hipotesis asosiatif bila masing masing variabel yang dihubungkan berbentuk ordinal dan rumusnya adalah (Sugiyono, 2010:356) :

\section{Rumus 1}

Analisis Korelasi Rank Spearman

$$
\rho=1-\frac{6 \Sigma b_{i^{2}}}{n\left(n^{2}-1\right)}
$$

Keterangan :

$\rho$ : Koefisien korelasi Rank Spearman

$\Sigma b_{i}{ }^{2}$ : Total kuadrat selisih antar ranking

$\mathrm{N}$ : Jumlah sampel yang diteliti

Arah korelasi dinyatakan dalam tanda + (plus) dan - (minus) dan nilai $r$ dan $\rho$ akan dikonsultasikan dengan tabel interpretasi nilai $r$ :

Tabel 2

Tabel Interpretasi Nilai $\mathbf{r}$

\begin{tabular}{|c|c|}
\hline Interval Koefisien & Tingkat Hubungan \\
\hline $0,000-0,199$ & Sangat Rendah \\
\hline $0,200-0,399$ & Rendah \\
\hline $0,400-0,599$ & Cukup \\
\hline $0,600-0,799$ & Kuat \\
\hline $0,800-1,000$ & Sangat Kuat \\
\hline
\end{tabular}

2. Uji Signifikansi Koefisien Korelasi Rank Spearman

a. Formula Hipotesis

$$
\begin{aligned}
& \mathrm{H}_{0}: \rho=0 \text { Tidak terdapat } \\
& \text { pengaruh knowledge } \\
& \text { management } \quad\left(\mathrm{X}_{1}\right) \\
& \text { dengan kinerj } \\
& \text { karyawan (Y) pada PT. } \\
& \text { Asaputex Jaya Kota } \\
& \text { Tegal. } \\
& \mathrm{H}_{1}: \rho \neq 0 \text { Terdapat pengaruh } \\
& \text { knowledge } \\
& \text { management } \quad\left(\mathrm{X}_{1}\right) \\
& \text { dengan kinerja } \\
& \text { karyawan (Y) pada } \\
& \text { PT.Asaputex Jaya Kota } \\
& \text { Tegal. } \\
& \mathrm{H}_{0}: \rho=0 \text { Tidak terdapat } \\
& \text { pengaruh stress kerja }
\end{aligned}
$$

$\left(\mathrm{X}_{2}\right)$ dengan kinerja karyawan (Y) pada PT. Asaputex Jaya Kota Tegal.
$\mathrm{H}_{2}: \rho \neq 0$ Terdapat pengaruh stress kerja $\left(\mathrm{X}_{2}\right)$ dengan kinerja karyawan (Y) pada PT. Asaputex Jaya Kota Tegal.

b. Taraf Signifikan

Menggunakan tingkat signifikan sebesar $95 \%$ (atau $\alpha=5 \%=$ $0,05)$.

c. Kriteria Pengujian Hipotesis

$\mathrm{H}_{0}$ diterima $:-\mathrm{t} \alpha / 2 \leq \mathrm{t} \leq \mathrm{t} \alpha / 2$

$\mathrm{H}_{0}$ ditolak $\quad: \mathrm{t}>\alpha / 2$ atau $\mathrm{t}<-\mathrm{t}$ $\alpha / 2$

d. Menghitung Nilai $t_{\text {hitung }}$

Adapun untuk menguji signifikansi dengan digunakan rumus sebagai berikut (Sugiyono, 2017:230) :

$$
\begin{gathered}
\mathbf{t}_{\text {hitung }} \\
t=\frac{r \sqrt{n-2}}{\sqrt{1-r^{2}}}
\end{gathered}
$$

Keterangan :

$\mathrm{T}$ : Besarnya $\mathrm{t}_{\text {hitung }}$

$\mathrm{R}$ : Koefisien korelasi

$\mathrm{N}$ : Jumlah sampel

e. Kesimpulan : $\mathrm{H}_{0}$ diterima atau ditolak.

3. Analisis Korelasi Berganda

Analisis korelasi berganda bertujuan untuk mengetahui kuat tidaknya variabel bebas yang berpengaruh secara bersama - sama terhadap variabel terikat, maka digunakan rumus sebagai berikut (Sugiyono, 2010:256) : 


\author{
Rumus 3 \\ Analisis Korelasi Berganda \\ $R y x 1 \times 2=\sqrt{\frac{\left(r^{2} y x 1+r^{2} y x 2\right)-2(r y x 1 r y x 2 r x 1 \times 2)}{1-r^{2} x 1 \times 2}}$ \\ Keterangan : \\ $\mathrm{R}_{\mathrm{yx} 1 \mathrm{x} 2}$ : Korelasi antara variabel $\mathrm{X}_{1}$ \\ dan $\mathrm{X}_{2}$ secara bersama - sama \\ $\mathrm{r}_{\mathrm{yx} 1}$ : Korelasi antara $\mathrm{X}_{1}$ dengan $\mathrm{Y}$ \\ $\mathrm{r}_{\mathrm{yx} 2}$ : Korelasi antara $\mathrm{X}_{2}$ dengan $\mathrm{Y}$ \\ $\mathrm{r}_{\mathrm{x} 1 \times 2}$ : Korelasi antara $\mathrm{X}_{1}$ dan $\mathrm{X}_{2}$
}

4. Uji Signifikansi Koefisien Korelasi Berganda

a. Formula Hipotesis

$$
\begin{aligned}
& \mathrm{H}_{0}: \rho=0 \text { Tidak terdapat } \\
& \text { pengaruh knowledge } \\
& \text { mnagement }\left(\mathrm{X}_{1}\right) \text { dan } \\
& \text { stress kerja }\left(\mathrm{X}_{2}\right) \text { secara } \\
& \text { bersama - sama dengan } \\
& \text { kinerja karyawan (Y) } \\
& \text { pada PT. Asaputex } \\
& \text { Jaya Kota Tegal. } \\
& \text { Terdapat pengaruh } \\
& \text { knowledge } \\
& \mathrm{H}_{1}: \rho \neq 0 \text { management }\left(\mathrm{X}_{1}\right) \text { dan } \\
&\text { stress kerja (X } \left.{ }_{2}\right) \text { secara } \\
& \text { bersama - sama dengan } \\
& \text { kinerja karyawan (Y) } \\
& \text { pada PT. Asaputex } \\
& \text { Jaya Kota Tegal. }
\end{aligned}
$$

b. Taraf Signifikan

Menggunakan tingkat signifikan sebesar $95 \%$ (atau $\alpha=5 \%=$ 0,05).

c. Kriteria Pengujian Hipotesis

$\mathrm{H}_{0}$ ditolak $: \mathrm{F}_{\text {hitung }}>\mathrm{F}_{\text {tabel }}$

$\mathrm{H}_{0}$ diterima $: \mathrm{F}_{\text {hitung }}<\mathrm{F}_{\text {tabel }}$

d. Menghitung Nilai $F_{\text {hitung }}$

Adapun untuk menguji signifikansi dengan digunakan rumus sebagai berikut (Sugiyono, 2017:235) :

\section{Rumus 4 \\ F $_{\text {hitung }}$}

$$
F_{\text {hitung }}=\frac{R^{2} / k}{\left(1-R^{2}\right) /(n-k-1)}
$$

Keterangan :

$\mathrm{F}$ : Besarnya $\mathrm{F}_{\text {hitung }}$

$\mathrm{R}$ : Koefisien korelasi berganda

$\mathrm{k}$ : Jumlah variabel bebas

$\mathrm{n}$ : Jumlah sampel

Kesimpulan : $\mathrm{H}_{0}$ diterima atau ditolak.

5. Uji Koefisien Determinasi

Digunakan untuk menjelaskan seberapa besar atau kecilnya (sumbangan langsung) variabel bebas dan variabel terikat dan rumusnya adalah :

Rumus 5

Koefisien Determinasi

$$
\mathrm{Kd}=\mathrm{R}^{2} \times 100 \%
$$

Keterangan :

$\mathrm{Kd}$ : Koefisien determinasi

$\mathrm{R}^{2}$ : Koefisien korelasi

\section{Hasil}

Penelitian ini dilakukan kepada 65 karyawan responden dan pada penelitian ini responden digambarkan berdasarkan jenis kelamin dan umur tercantum dalam tabel di bawah ini :

\subsection{Profil Responden Menurut Jenis Kelamin}

Deskripsi profil responden menurut jenis kelamin adalah pengelompokan responden menurut jenis kelamin laki - laki dan perempuan. Untuk mengetahui tingkat proporsi jenis kelamin laki - laki dan perempuan, maka dapat disajikan melalui tabel berikut :

\section{Tabel 3}

Profil Responden Menurut Jenis kelamin

\begin{tabular}{|c|c|c|c|}
\hline No & Jenis Kelamin & Jumlah & Prosentase \\
\hline 1 & Laki - laki & 23 & $35 \%$ \\
\hline 2 & Perempuan & 42 & $65 \%$ \\
\hline & Jumlah & 100 & $100 \%$ \\
\hline
\end{tabular}


Berdasarkan tabel 3 di atas dapat diketahui bahwa perempuan menjadi karyawan yang mendominasi yaitu terdapat 42 orang atau $65 \%$ dan laki - laki berjumlah 23 orang atau $35 \%$.

\subsection{Profil Responden Menurut Umur}

Deskripsi profil responden menurut umur menggambarkan tingkat pengalaman dan kedewasaan pola pikir seorang responden karyawan di PT. Asaputex Jaya Kota Tegal yang dapat disajikan melalui tabel berikut :

Tabel 4

\section{Profil Responden Menurut Umur}

\begin{tabular}{|c|c|c|c|}
\hline No & Umur & Jumlah & Prosentase \\
\hline 1 & $<20$ Tahun & 0 & $0 \%$ \\
\hline 2 & $21-25$ Tahun & 5 & $8 \%$ \\
\hline 3 & $26-30$ Tahun & 40 & $61 \%$ \\
\hline 4 & $>30$ Tahun & 20 & $31 \%$ \\
\hline & Jumlah & 65 & $100 \%$ \\
\hline
\end{tabular}

Berdasarkan tabel 4 di atas dapat diketahui bahwa umur responden karyawan pada PT. Asaputex Jaya Kota Tegal banyak yang berusia 26 - 30 tahun menduduki jumlah terbanyak yaitu 40 orang atau $61 \%$. Umur direntang $26-30$ tahun lebih mendominasi dikarenakan umur tersebut lebih produktifdalam bekerja di PT. Asaputex Jaya Kota Tegal.

\subsection{Analisis Korelasi Rank Spearman} Knowledge Management Terhadap Kinerja Karyawan

Untuk menjawab pengujian hipotesis pertama, yaitu "Terdapat pengaruh knowledge management terhadap kinerja karyawan pada PT. Asaputex Jaya Kota Tegal." dilakukan dengan menggunakan analisis korelasi rank spearman. Berikut ini adalah hasil pengujian hipotesis pertama dengan menggunakan analisis korelasi rank spearman :
Tabel 5

Hasil Uji Korelasi Rank Spearman

Knowledge management Terhadap Kinerja Karyawan

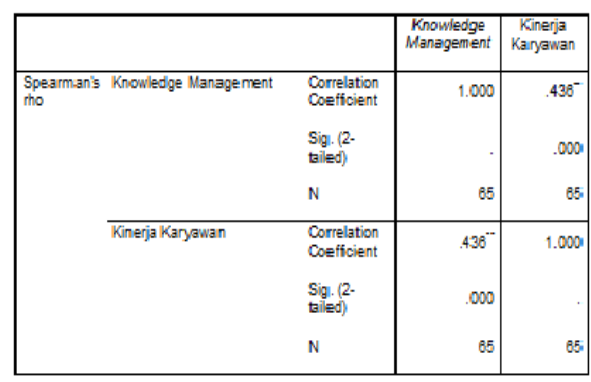

Berdasarkan data hasil output diatas tertera nilai kefesien korelasi rank spearman yaitu sebesar 0,436. Apabila nilai koefesien korelasi ini diinterprsestasikan dengan kategori penilaian maka berada dalam nilai korelasi antara $0,400-0,600$ yang berarti status hubungan cukup kuat. Oleh karena itu maka hubungan antara variabel Knowledge Management terhadap Kinerja Karyawan merupakan hubungan cukup kuat. Maka hal ini jika knowledge management nya bagus tentudapat meningkatkan kierja karyawan begitu juga sebaliknya.

\section{Tabel 6}

Hasil Uji Korelasi Rank Spearman Stress kerja Terhadap kinerja karyawan

\begin{tabular}{|c|c|c|c|}
\hline & & Stres Keja & $\begin{array}{c}\text { Kinerja } \\
\text { Karyewan }\end{array}$ \\
\hline $\begin{array}{l}\text { Spearman's Stes Kerja } \\
\text { tho }\end{array}$ & $\begin{array}{l}\text { Correlation Cosficient } \\
\text { Sig. (2-tailed) } \\
\text { N }\end{array}$ & $\begin{array}{r}1.000 \\
65 \\
\end{array}$ & $\begin{array}{r}.496 \\
.005 \\
65\end{array}$ \\
\hline Kinerja Karyawan & $\begin{array}{l}\text { Correlation Cosficient } \\
\text { Sig. (2-tailed) } \\
\text { N }\end{array}$ & $\begin{array}{r}.496 \\
.000 \\
65\end{array}$ & $\begin{array}{r}1.000 \\
. \\
65\end{array}$ \\
\hline
\end{tabular}

Berdasarkan data hasil output diatas tertera nilai kefesien korelasi rank spearman yaitu sebesar 0,496. Apabila nilai koefesien korelasi ini diinterprsestasikan dengan kategori penilaian maka berada dalam nilai korelasi 
antara $0,400-0,600$ yang berarti status hubungan cukup kuat. Oleh karena itu maka hubungan antara variabel Stres Kerja terhadap Kinerja Karyawan merupakan hubungan cukup kuat. Hal ini jika perusahaan meperdulikan tugas karyawan tentu karyawan tidak merasa jenuh yang dapt mengakibatkan peningkatan atau penurunan kinerja karyawan.

4.4 Analisis Korelasi Berganda

Menurut Sugiyono (2016:222) korelasi berganda digunakan untuk mengukur hubungan secara kuantitatif antar variabel independen secara bersama sama terhadap variabel dependen. Yaitu knowledge management (X1), stress kerja (X2) terhadap kinerja karyawan (Y) yang dapat dihitung secara manual yaitu sebagai berikut :

$$
\left(1-R_{\mathrm{y} 12}^{2}\right)=\left(\begin{array}{lll}
\left(1-r_{\mathrm{y} .1}^{2}\right. & \left(1-r_{\mathrm{y} 2.1}^{2}\right.
\end{array}\right)
$$

Tabel 7

Hasil Uji Korelasi Berganda

Knowledge Management dan

Stress kerja Terhadap kinerja karyawan

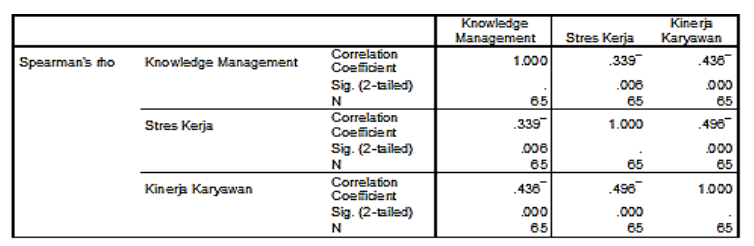

Adapun perhitungan koefesien adalah sebagai berikut :

a. Mencari nilai $r$ y2.1 dengan menggunakan rumus sebagai berikut :

$$
\mathrm{r}_{\mathrm{y} 2.1}=\frac{r_{y 2}-r_{y 1} \cdot r_{1.2}}{\sqrt{\left(1-r^{2}{ }_{y 1}\right)\left(1-r^{2} 1.2\right)}}
$$

Dimana :

$$
\begin{aligned}
& r_{\mathrm{y} 2}=0,496 \\
& r_{\mathrm{y} 1}=0,436 \\
& r_{12}=0,339 \\
& r_{\mathrm{y} 2.1}=\frac{0,496-0,436 \times 0,339}{\sqrt{(1-0,246)(1-0,114)}} \\
& r_{\mathrm{y} 2.1}=\frac{0,496-0,147}{\sqrt{0,754 \times 0,886}}
\end{aligned}
$$

$$
\begin{aligned}
r_{\mathrm{y} 2.1} & =\frac{0,349}{\sqrt{0,668}} \\
r_{\mathrm{y} 2.1} & =\frac{0,349}{0,817} \\
r_{\mathrm{y} 2.1} & =0,427
\end{aligned}
$$

b. Mencari nilai korelasi berganda (R) dengan menggunakan rumus sebagai berikut :

$$
\begin{aligned}
& \left(1-R^{2} y_{.12}\right)=\left(1-r_{y 1}^{2}\right)\left(1-r^{2}{ }_{y 2.1}\right) \\
& \text { Dimana }: \\
& r_{y 1}=0,436 \\
& r_{y 2.1}=0,427 \\
& \left(1-R^{2} y_{.12}\right)=\left(1-r^{2}{ }_{y 1}\right)\left(1-r^{2}{ }^{2} 2.1\right) \\
& \left(1-R^{2} y_{.12}\right)=\left(1-0,436^{2}\right)\left(1-0,427^{2}\right) \\
& \left(1-R^{2} y_{.12}\right)=(1-0,190)(1-0,182) \\
& \left(1-R^{2} y_{.12}\right)=(0,81)(0,818) \\
& \left(1-R^{2} y_{.12}\right)=(0,654) \\
& R=\left(1-0,654^{2}\right) \\
& R=(1-0,427) \\
& R=0,573
\end{aligned}
$$

Dari hasil perhitungan korelasi berganda diatas dengan cara manual maka dapat diperoleh nilai $\mathrm{R}=0,573$. Nilai sebesar 0,573 berada di interval koefesien korelasi 0,400 - 0,600. Hal ini dapat menunjukan hubungan yang tergolong cukup kuat antara variabel knowledge management dan stress kerja secara simultan terhadap kinerja karyawan dan bersifat positif.

\subsection{Uji Signifikansi Koefisien Korelasi} Berganda

a. Formula Hipotesis

$H_{0}: \rho=0, \quad$ Tidak terdapat pengaruh yang signifikan antara knowledge management (X1) dan stress kerja (X2) secara bersama - sama terhadap kinerja karyawan (Y) pada PT. Asaputex Jaya Kota Tegal.

$H \mathrm{a}: \rho \neq 0, \quad$ Terdapat pengaruh yang signifikan antara knowledge management (X1) dan stress kerja (X2) terhadap kinerja karyawan (Y) pada PT. Asaputex Jaya Kota Tegal.

b. Taraf Signifikan

Dalam penelitian ini menggunakan taraf signifikan sebesar sebesar $95 \%$ 
atau $(\alpha=5 \%)$.

c. Kriteria Pengujian Hipotesis

Kriteria ntuk menolak atau menerima

$\mathrm{H}_{0}$ adalah :

$\mathrm{H}_{0}$ di tolak jika $=\mathrm{F}_{\text {hitung }}>\mathrm{F}_{\text {table }}$

$\mathrm{H}_{0}$ di terima jika $=\mathrm{F}_{\text {hitung }}<\mathrm{F}_{\text {tabel }}$

Pengujian

Untuk menguji korelasi berganda, uji statistiknya menggunakan rumus umum uji $F$ sebagai berikut.

$$
\begin{aligned}
& F_{0}=\frac{R^{2} / k}{\left(1-R^{2}\right) /(n-k-1)} \\
& F_{0}=\frac{0,573^{2} / 2}{\left(1-0,573^{2}\right) /(65-2-1)} \\
& F_{0}=\frac{0,328 / 2}{0,672 / 62} \\
& F_{0}=\frac{0,164}{0,010838} \\
& F_{0}=15,131
\end{aligned}
$$

Dari uji signifikansi koefesien korelasi berganda di atas diperoleh nilai $F$ hitung sebesar 15,131. Nilai $F$ hitung sebesar 15,131 tersebut selanjutnya dibandingkan dengan $\mathrm{F}$ tabel 3,15. Karena $\mathrm{F}$ hitung $>\mathrm{F}$ tabel $(15,131>3,15)$ artinya ada pengaruh Knowledge management dan stress kerja secara bersama - sama terhadap kinerja karyawan.

4.6 Analisis Koefiisien Determinasi

Menurut Ghozali (2012: 97) koefisien determinasi merupakan alat untuk mengukur seberapa jauh kemampuan model dalam menerangkan variasi variabel dependen.

$\mathrm{D}=\mathrm{r}^{2} \mathrm{x} 100 \%$

Keterangan :

$\mathrm{D}=$ Koefesien Determinasi

$\mathrm{R}=$ Koefesien Korelasi Berganda $(\mathrm{R}=$ $0,573)$

Jawab :

$\mathrm{D}=\mathrm{R}^{2} \times 100 \%$

$\mathrm{D}=(0,573)^{2} \times 100 \%$
$\mathrm{D}=0,328 \times 100 \%$

$\mathrm{D}=32,8 \%$

Berdasarkan nilai koefesiensi determinasi diatas perhitungan secara manual, diperoleh sebesar 0,328. Dapat disimipulkan bahwa kontribusi variabel knowledge management dan stress kerja terhadap kinerja karyawan sebesar 32,8 $\%$ sedangkan sisanya 67,2\% disebabkan oleh faktor lain yang tidak dapat di jelaskan.

\section{Kesimpulan Dan Saran}

5.1 Kesimpulan

Berdasarkan hasil penelitian tentang pengaruh Implementasi Knowledge Management dan Stres Kerja Terhadap Kinerja Karyawan Pda PT. Asaputex Jaya Kota Tegal dapat ditarik kesimpulan sebagai berikut :

1) Terdapat pengaruh yang cukup kuat, positif dan signifian variabel knowledge management terhadap kinerja karyawan pada PT. Asaputex Jaya Kota Tegal. Dibuktikan dengan hasil perhitungan korelasi rank spearman knowledge management terhadap kinerja karyawan pada PT. Asaputex Jaya Kota Tegal. Dengan diperolehnya nilai korelasi sebesar 0,436 .

2) Terdapat pengaruh yang cukup kuat, positif dan signifikan variabel stress kerja terhadap kinerja karyawan pada PT. Asaputex Jaya Kota Tegal. Dibuktikan dengan hasil perhitungan korelasi rank spearman stress kerja terhadap kinerja karyawan pada PT. Asaputex Jaya Kota Tegal. Dengan diperolehnya nilai korelasi sebesar 0,496 . .

3) Terdapat pengaruh yang cukup kuat, positif dan signifikan antara 
variabel knowledge management dan stress kerja secara bersama sama terhadap kinerja karyawan pada PT. Asaputex Jaya Kota Tegal. Dibuktikan dengan dari hasil perhitungan korelasi berganda diperoleh nilai $\mathrm{R}$ sebesar 0,573 .

\subsection{Saran}

Berdasarkan kesimpulan yang diperoleh dalam penelitian ini, maka diajukan saran sebagai pelengkap terhadap hasil penelitian yang dapat diberikan sebagai berikut :

1) Meningkatkan sebuah knowledge management bagi setiap karyawan pada perusahaan. Hal ini karyawan merupakan asset yang paling berharga bagi perusahan sehingga perlu adanya peningkatan sebuah kualitas SDM mlealui knowledge management agar karyawan mengusai dalam segala tugas yang diberikan oleh perusahan sehingga dalam hal ini perusahaan mempunyai karyawan yang berkualitas yang nantinya dapat meningkatkan kinerja karyawan yang menghasilkan sebuah keuntungan atau laba bagi perusahaan itu sendiri.

2) Perlu adanya tugas pekerjaan yang jelas yang akan nantinya dapat mempermudah karyawan dalam menjalankan tugas agar karyawan dengan santai megerjakan sesuai dengn tugas yang ia dapat tanpa adanya kebingungan yang mengakibatan kerugian bagi perushaan.

3) Tidak memberikan tugas ganda pada karyawan yang tidak dapat melakukanya yang mengakibatkan stress kerja pada karyawan.

4) Selalu mengadakan evaluasi kerja di akhir bulan agar ketika ada masalah sekecil apapun diperusahan dapat secara cepat terselesaikan untuk menghindari inflasi pada peruahaan.

5) Pihak perusahaan selalu bersifat terbuka pada setiap forum organisasi perusahaan agar setiap karyawan dapat memahami dan mengerti apa yang diminta oleh perusahaan.

\section{DAFTAR PUSTAKA}

Agung. (2018, 12 23). Definisi Kinerja. Retrieved 04 07, 2017, from Definisi Kinerja: http:definisimu.blogspot.com

Andreas, C. (2017, 09 08). Metode Pengumpulan Data Dalam Penelitian. Retrieved 02 08, 2016, from Metode Pengumpulan Data Dalam Penelitian: http://ciputrauceo.net/blog

Andrian, C. I. (2016). "Implementasi Knowledge Manajemen dan Pengaruhnya terhadap Kineja Karyawan". Jurnal Ekonomi Manajemen ， 1-10. (2019,09,23) http://int.search.myway.com/search/GG main.jhtml

Anshor, \& Kosashi. (2007). Knowledge Management. Surabaya: Citra Abadi.

Arifianto, M. D. (2012). Ekonometrika Teori dan Aplikasi. Jakarta: PT. Gelora Agkasa Pratama.

Arikunto, Suharsimi, \& Likert. (1998). Prosedur Penelitian Suatu Pendekatan Praktek. Jakarta: PT. Rineka Putra.

Bhojaraju. (2005). "Knowledge Management". Jurnal Ekonomi , 38.

Damayanti, E. (2001). "Stres kerja dilingkungan DPRD". Jurnal masyrakat, 73-84.

Dapper, \& Smith. (1992). Analisis Regresi Terapan. Jakarta: PT. Gramedia 
Pustaka Utama.

Dharma. (2005). Manajemen Kinerja . Jakarta: Bumi Aksara.

Fahmi, I. (2017). Manajemen Kinerja Teori dan Aplikasi. Bandung: ALFABETA.

Fifi. (2013). "Analisis Pengaruh Knowledge Manajement terhadap Keunggulan Bersaing dan Kinerja Perusahaan". Jurnal Akuntansi Bisnis , 161171.(2018,11,24)http://publication.petra .ac.id/index.php/akuntansibisnis/article/view/817

Ghazali, I. (2014, 11 23). "Stres Kerja terhadap Kinerja Karyawan". Retrieved 03 30, 2014, from Stres Kerja terhadap Kinerja Karyawan: https://www.researchgate.net/piblicatio $\underline{\mathrm{n}}$

Ghazali, I., \& Veithzal. (2009). Aplikasi Ananlisis Multivariate edisi ke empat dengan Program SPSS. Semarang: Universitas Diponegoro.

Gitusudarmo, \& D. 1. (2000). Perilaku Organisasi Edisi Pertama. Jogjakarta: Erlangga.

Handoko, \& Han. (2018). Manajemen Personalia. Yogyakrta: BPFE Yogyakarta.

Hanoyo, Seger, \& Sulistyono. (2001). "Stres Pada Masyrakat Surabaya". Jurnal Median Insan Psikolog 3, 61-74.

Hasan, \& Davidson. (2002). Pokok Pokok Materi Statistik. Jakarta: Bumi Aksara.

Hasbuan, Malayu, \& Delimawati. (2012). Manajemen Sumber Daya Manusia edisi revisi. Jakarta: Bumi Aksara.

Hasibuan, H. (2014). Manajemen Personalia dan Sumber Daya Manusia. Yogyakarta: BPFE Yogyakarta.
Ikhramawati. (2016). "Pengaruh Knowledge Manajement terhadap Kinerja Karyawan". Jurnal Manajemen dan Bisnis 2289.(2018,09,16)https://media.neliti.com /media/publications/188340-IDpengaruh-knowledge-managementterhadap-k.pdf

Imam, G., Yuli, \& Honeycutt. (2005). Aplikasi Analisis Multivariate dengan Program SPSS edisi kedua. Semarang: Badan penerbit Universitas Diponegoro.

Kristianti. (2012). "Pengaruh Stres Kerja dan Motivasi terhadap Produktivitas Kerja di BPJS Kesehatan KCU Bogor". Jurnal Ekonomi MSDM, 12-23. (2018,12,27)http://p2m.polibatam.ac.id/ wp-content/uploads/2018/02/306-1331185-1-10-20170727.pdf

Lucas. (2009). Manajemen Sumber Daya Manusia. Jakarta: PT. Cipta Karya.

Lutfhan. (2011). "Pengaruh Stres Kerja dan Kepuasan Kerja terhadap Kinerja Perawat". Jurnal Ekonomi dan Penerapannya 76-98. (2018,11,23)http://jp.feb.unsoed.ac.id/in dex.php/jeba/article/viewFile/1156/128 $\underline{3}$

Malayu, \& Hasibuan. (2006). Manajemen Sumber Daya Danusia. edisis revisi cetakan ke delapan. Jakarta: Bumi Aksara.

Mangkunegoro, Bambang, Timpe, Bernardin, Agus, \& Henry. (2005). Evaluasi Kinerja Sumber Daya Manusia. Bandung: Refika Aditama.

Masana, S. (2012). "Budaya dan Kinerja Organisasi". Jurnal Ensiklopedia Ekonomi,81.(2018,12,12)https://media. neliti.com/media/publications/265989analisis-pengaruh-budaya-organisasi- 
terh-2cb44b46.pdf

Muhammad. (2016). "Pengaruh Knowledge Manajemen terhadap Kinerja Karyawan pada PT. PLN Distributor Jawa Timur". Jurnal Umum Manajemen ,6283. $(2018,11,14)$

http://journal.unair.ac.id/LN@pengaruh -knowledge-management-terhadapkinerja-karyawan-pt.-pln-distribusijawa-timur-article-10823-media-136category-8.html

Nuryandi, T. A., \& Tampi. (2015). "Pengaruh Stres Kerja terhadap Kinerja Karyawan pada PT, Bank Pengkreditan Rakyat dana raya Manado". Jurnal Pengetahuan Manajemen , 11-23. $(2018,09,23)$

https://ejournal.unsrat.ac.id/index.php/ja b/article/view/15690

Pengabean. (2007). Manajemen Sumber Daya Manusia. Bandung: Refika Aditama.

Polanyci. (1996). Arti Manajemen. Malang: Soetmojo Adjipita.

Robbin, Stephen, \& Timonty. (2008). Perilaku Organisasi. Jakarta: Salemba Empat.

Sasongko, W., Deven, \& Martin. (2010). Psikologi Industri dan Organisasi. Jakarta: PRANEDANA MEDIA GROUP.

Sasono, Eko, Cariovietal, Rivai, \& Gujarati. (2004). Mengelola Stres Kerja. Semarang: Universitas Padjajaran.

Sedarmayanti. (2017). Perencanaan dan Pengembangan SDM. Bandung: Revika Aditama.

Singarimbun, \& Efendi. (2002). Operasional Variabel pada Penelitian. Jakarta: PT. Surya Abadi.

Sugiyono. (2012). Metode Penelitian Bisnis.
Bandung: ALFABETA.80-231

Suharshimi (2010). Prosedur Suatu Penelitian Pendekatan Praktek. Jakarta: Citra

Abadi. 211-239

Wulantika. (2009). Manajemen Pengetahuan (Knowledge Management). Jakarta: Angkasa Putra. 